\title{
Mitochondrial Genome Profile in Demyelinating Diseases
}

Durastanti $\mathbf{V}^{1 *}$, Monaco $\mathrm{A}^{2,3}$, Caronti $\mathrm{B}^{1}$, Cortese $\mathrm{A}^{1}$, Fustaino $\mathrm{V}^{3}$, Wang $\mathrm{E}^{2}$, Berardelli $\mathrm{A}^{1}$, Marincola $\mathrm{FM}^{2}$ and Millefiorini $\mathrm{E}^{1}$

${ }^{1}$ Department of Neurology and Psychiatry, Sapienza University, Rome, Italy

${ }^{2}$ Department of Transfusion Medicine, National Institutes of Health, Bethesda, MD, USA

${ }^{3}$ Department of Cellular Biotechnology and Ematology, Sapienza University, Rome, Italy

\begin{abstract}
Multiple sclerosis and neuromyelitis optica are chronic inflammatory diseases of the central nervous system. These pathologies share clinical similarities with Leber hereditary optic neuropathy, which is primarily due to mutations of mitochondrial DNA. Mitochondrial genetic variations may influence susceptibility to develop multiple sclerosis and neuromyelitis optica. In order to explore the possible correlation between mitochondrial DNA specific patterns and demyelinating diseases involving central nervous system, mitochondrial DNA from 13 patients with relapsing-remitting multiple sclerosis, 4 patients with neuromyelitis optica, 1 patient with myelitis, 2 patient with optic neuritis, and 7 healthy controls were analyzed by sequencing the full length $16 \mathrm{Kbs}$ of the mitochondrial DNA genome. Common variants presence in healthy controls and patients showing no clinical impact on diseases development were not further explored. Analyzing 414 patient specific variants, six nonsense mutations, causing early stop-codon formation, and nine previously described variants, associated with demyelinating/degenerative disease of central nervous system were identified. Some of these variants are linked to disease development through known and previously described mechanisms. We report for the first time other truncating mutations leading to incomplete proteins involved in Oxidative Phosporilation complexes and we speculate their role in demyelinating diseases development.
\end{abstract}

Keywords: Mitochondrial diseases; Multiple sclerosis; Neuroophtalmology

\section{Introduction}

Multiple sclerosis (MS) is a chronic inflammatory neurological disease of the central nervous system (CNS), characterized by demyelination, neurodegeneration and astroglial proliferation [1], with complex genetic factors exerting a profound influence [2]. Despite major advances in the current understanding of the pathogenesis of MS, the inflammatory cascade involved in MS remains unknown; although there is considerable evidence implicating the involvement of mitochondria in axonal and glial injury mechanisms $[3,4]$.

Similarly to MS, neuromylitis optica (NMO), or Devic's disease, is a demyelinating disease of the CNS characterized by optic neuritis $(\mathrm{ON})$ and myelitis (My) [5] associated with anti-aquaporin 4 (AQP4) antibodies detectable in the serum [6]. Several siblings with NMO have been reported $[7,8]$, raising the possibility of a genetic predisposition, but no pathogenic mutations have been identified in the AQP4 gene on chromosome 18q11.2-q12.1 [9].

MS and NMO have similarities with Leber hereditary optic neuropathy (LHON, MIM 535 000), which is the commonest cause of isolated blindness in young men. LHON is primarily due to mutations of mitochondrial DNA (mtDNA) that disrupt complex I of the respiratory chain $[10,11]$. Moreover, some patients, with mtDNA mutations causing LHON, develop a demyelinating disease, which is clinically and radiologically indistinguishable from MS [12].

Mitochondria are unique amongst cellular organelles for having their own distinct genome, separate from nuclear DNA (nDNA). This mtDNA, which is 16,569 base pairs in length, contains a total of 37 genes - 2 ribosomal RNAs (rRNAs), 22 encoding transfer RNAs (tRNAs) and 13 encoding polypeptides. The polypeptides subunit are components of the respiratory chain, including complex I (NADH dehydrogenase-ubiquone oxidoreductase), complex III (ubiquinonecytochrome $c$ oxidoreductase), complex IV (cytochrome $c$ oxidase), and complex V (ATP synthetase) [13].

Previous studies reported that various mitochondrial mechanisms are involved in the pathogenesis of MS and other demyelinating disease of CNS [14-17]. In particular, several studies, linking mitochondrial genome abnormalities to oxidative damage and inflammation, strongly suggest that an acquired mitochondrial dysfunction may be contribute to neurodegeneration in MS $[15,16,18]$. This finding is supported by a decreased expression of several mitochondrial proteins and a reduced activity of complexes I and III detected in the MS motor cortex [4]. Furthermore, mitochondria is one of the prime cellular sources of reactive oxygen species (ROS) which play a role together with reactive nitric species (RNS) in the development of axonal degeneration $[19,20]$. Since the extent of ROS formation is a function of the oxygen consumption, higher levels of ROS are produced by neurons mitochondria with higher metabolic activity or by neuronal segments enriched in mitochondria, such as synapses. Neurons are particularly vulnerable to the oxidative stress induced by ROS. Furthermore, the overproduction of nitric oxide (NO) and its oxidative metabolites is one of the distinct characteristics of inflammatory CNS diseases including MS and EAE [21-24]. Thus, in conclusion, it is likely that oxidative damage in CNS inflammatory diseases may originates mainly from mitochondria [25].

Given the clinical similarities between NMO and LHON, previous investigators have also looked for specific mtDNA mutations in patients with NMO [26-30], while others have studied polymorphic variation of mtDNA in NMO cases [27,28,31,32]; a subtle increased susceptibility conferred by rare mtDNA variants could not be excluded

*Corresponding author: Valentina Durastanti, Department of Neurological Sciences, Viale Università 30, 00185 Rome, Italy, Tel: +39-06-4457711; Fax: +39064457711; E-mail: valentina.durastanti@uniroma1.it

Received November 08, 2013; Accepted November 28, 2013; Published December 06, 2013

Citation: Durastanti V, Monaco A, Caronti B, Cortese A, Fustaino V, et al. (2013) Mitochondrial Genome Profile in Demyelinating Diseases. J Neurol Neurophysiol 4: 179. doi:10.4172/2155-9562.1000179

Copyright: (c) 2013 Durastanti V, et al. This is an open-access article distributed under the terms of the Creative Commons Attribution License, which permits unrestricted use, distribution, and reproduction in any medium, provided the original author and source are credited. 
[30], although the recruitment of samples sizes large enough to show a statistical significant association between specific mtDNA variants and complex diseases may be extremely challenging [33].

Despite results previously described, the exact role of mtDNA and especially mtDNA's polymorphism in MS and NMO has not been fully characterized.

In our study we aimed at determining a possible correlation between mtDNA specific patterns and demyelinating diseases involving medulla and optic nerve. Particularly, we have sequenced and analyzed the whole mtDNA of a cohort of patients with relapsingremitting (RR) MS, NMO, My and ON in order to determinate a putative panel of deleterious mutations with a possible correlation with neurodegenerative diseases and establish their penetrance and their actual weight in the pathogenesis.

\section{Methods}

\section{Population}

The present explorative study included a total of 27 Caucasian individuals, 20 of which were patients ( 13 were diagnoses with RRMS, 4 with NMO, 2 with ON and 1 with My,) and 7 were healthy controls (HC). NMO and MS patients satisfied Wingerchuk [5] and Poser [34] diagnostic criteria, respectively. All subjects gave the informed consent.

\section{Specimen collection and genetic analysis}

Blood samples were collected into CPT sterile tubes (BD) and were a centrifuged at $3,000 \mathrm{rpm}$ for 10 minutes at $4^{\circ} \mathrm{C}$ for peripheral blood mononuclear cell (PBMC) isolation according the manual. Genomic DNA was extracted from PBMC using the DNeasy blood and tissue DNA extraction kit (Qiagen) according to manufacturer's instructions. Extracted Genomic DNA was then diluted to $30 \mathrm{ng} / \mu \mathrm{l}$, aliquoted and stored at $-20^{\circ} \mathrm{C}$.

The full coverage of mtDNA were amplified using mitoSEQr $r^{\text {rn }}$ Resequencing Primers Set (RSS000056015_01 mitoALL ${ }^{\mathrm{m}}$, Life Technologies), a system specifically designed and optimized for the amplification of $100 \%$ of human mitochondrial genome. This primer set consists 46 primers pairs designed in order to standardize the Polymerase Chain Reaction (PCR) conditions and the following sequence reaction. Each pre-designed primer pair generates a resequencing amplicon (RSA) marked with a M13 nucleotide sequence at both 5' ends, useful for simplifying the development of a sequence reaction. Through M13 primers the sequencing reaction can be set up using a single mastermix aliquoted into each well.

The PCR reaction included AmpliTaq Gold $2 x$ Master Mix, primers set (forward+reverse) and $30 \mathrm{ng}$ of the DNA sample in $20 \mu \mathrm{l}$ of total volume. Each amplicon was amplified in a single well of a 96well plate for each sample; each plate also included negative controls to ensure no possible contamination. Thermalcycler conditions were set up according to the manufacturer specifications. 2\% agarose gel electrophoresis was performed to test PCR products, and then the PCR was cleaned up from unused primers and dNTPs with the enzymatic method ExoSAP-IT (Affymetrix) according to the manufacturer's instructions.

All amplicons were sequenced using universal conditions. BigDye Terminator v3.1 Cycle Sequencing kit was used for the sequence reaction: in a total volume of $10 \mu \mathrm{l}$, sequencing was performed with BigDye Terminator Mix, purified PCR amplicons and M13 primer forward (or reverse when forward primer did not produced a readable sequence). Unincorporated dye terminators were removed with DyeEx 96 (QIAGEN) plate according to manufacturer's instructions.

Sequence reactions were analyzed on the 48-Capillary 3130xl Genetic Analyzer (Life technologies). AB1 files with sequencing info for each sample were extracted at the end of each run.

\section{Data analysis}

Using the software Sequencer 4.10.1 (http://genecodes.com) to analyse wild type sequences from mitochondrial genome obtained from healthy samples, we defined a reference wild type sequence to be compared to the samples in order to identify variants potentially associated with the diseases.

Einsencluster and Treeview (http://rana.lbl.gov/EisenSoftware. htm) softwares were used to generate heatmaps representing clusters of differential genetic profiles. Characterization of known variants (the one for which an $r s$ number was available) was performed using an online software Pupasuite (http://pupasuite.bioinfo.cipf.es/), an interactive web-based SNP analysis tool that allows for the selection of relevant SNPs within a gene, based on different characteristics of the SNP itself; the algorithm helped in identifying putative variants for which a previous association with specific disease had been described.

The variants identified by comparing the reference sequence with each sample was searched against gene variants information databases available online: GeneCards (http://www.genecards.org), Ensembl (http://www.ensembl.org), COSMIC (http://www.sanger. ac.uk/genetics/CGP/cosmic), LOVD (http://www.lovd.nl/2.0) UniProt (http://www.uniprot.org) and HGMD (http://www.hgmd.org).

\section{Results}

\section{Variants analysis}

Mitochondrial genome Sequencing of 27 samples (13 RRMS, 4 NMO, $2 \mathrm{ON}, 1 \mathrm{My}$ and $7 \mathrm{HC}$ ) highlighted the presence of total 414 variants present only in patients. Among them 74 were already classified in literature (and therefore registered with $r s$ number) and 340 were not previously described. Out of 414 variants, 121 were missense (generating an amino-acid exchange), 108 synonymous (variants occurring in coding region but not generating amino-acid exchange) and 185 intronic (occurred in non-coding regions of DNA sequence) variants. None of the variants described so far ever occurred in a HC patient (data not shown). The variants distribution in our cohort of patients is represented in Figure 1.

\section{Variants not previously described}

Out of 340 not previously described variants, we found 6 missense mutations generating stop codon and consequently a truncated protein with compromised function. These mutations were found in patients with RRMS, ON and My. All truncating mutations occurred in heteroplasmic condition except one. The features of these mutations are described in Table 1.

\section{Variants previously described}

Out of 74 variants already classified in literature we found 9 variants reported to have a clinical impact; none of these variants were present in the HC group (data not shown) analysed in the present study. The features of these variants are summarized in Table 2.

\section{Mitochondrial haplogroup typing}

Haplogroup for each individual of our cohort was established 
Citation: Durastanti V, Monaco A, Caronti B, Cortese A, Fustaino V, et al. (2013) Mitochondrial Genome Profile in Demyelinating Diseases. J Neurol Neurophysiol 4: 179. doi:10.4172/2155-9562.1000179

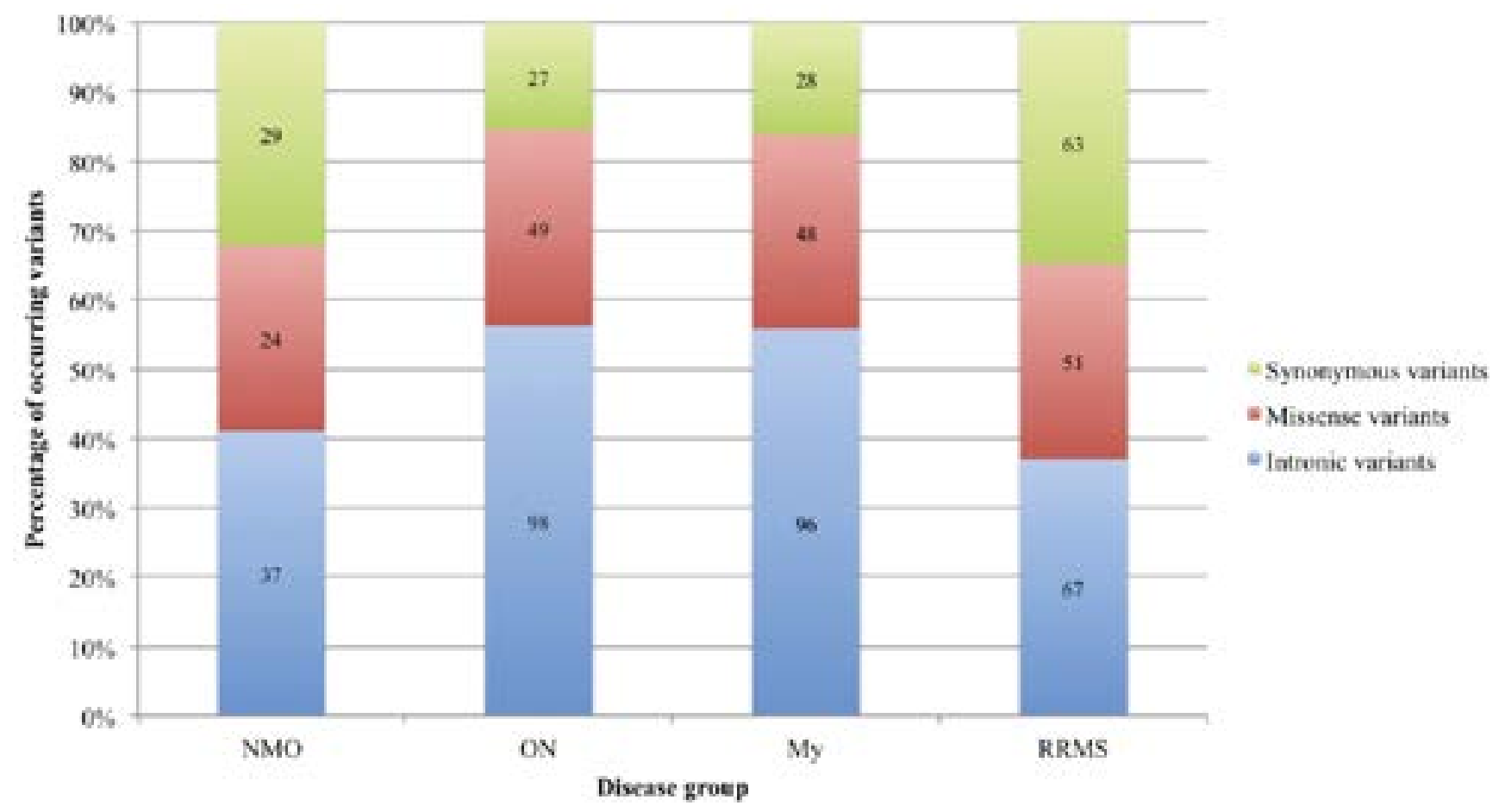

Figure 1: Variants distribution in different disease groups. NMO: neuromylitis optica, ON: optic neuritis, My: myelitis, RRMS: relapsing-remitting multiple sclerosis.

\begin{tabular}{|c|c|c|c|c|c|c|c|c|c|c|c|c|c|c|c|c|c|c|c|c|c|c|}
\hline & & & & & & & & $N$ & My & \multicolumn{13}{|c|}{$R R M S$} \\
\hline nt change & aa change & Protein & 1 & 2 & 3 & 4 & 5 & 6 & 7 & 8 & 9 & 10 & 11 & 12 & 13 & 14 & 15 & 16 & 17 & 18 & 19 & 20 \\
\hline $4989 \mathrm{C}>\mathrm{T}$ & Gln Stop & ND2 & & & & & & $+/-$ & $+/-$ & & & & & & & & & & & & & \\
\hline $5932 C>G$ & Thr 10 Stop & CYT1 & & & & & & $+/-$ & $+/-$ & & & & & & & & & & & & & \\
\hline $6893 C>G$ & Ser 329 Stop & CYT1 & & & & & & $+/-$ & $+/-$ & & & & & & & & & & & & & \\
\hline $6901 A>G$ & Lys 332 Stop & CYT1 & & & & & & & $+/-$ & & & & & & & & & & & & & \\
\hline $8528 \mathrm{~T}>\mathrm{G}$ & Met 1 Stop & ATP6 & & & & & & & & & & & & & & & & $+/-$ & & & & \\
\hline $15462 \mathrm{~T}>\mathrm{A}$ & Leu Stop & CYT-b & & & & & & $+/+$ & & & & & & & & & & & & & & \\
\hline
\end{tabular}

Table 1: Features of Nonsense Mutation Identified in the Study not Previously Described in Literature. +/- occurrence of mutation in heteroplasmic conditions while $+/+$ in homoplasmic. NMO: neuromyelitis optica, RRMS: relapsing-remitting multiple sclerosis, ON: optic neuritis, My:myelitis. ND2: NADH dehydrogenase subunit 2, CYT1: cytochrome c oxidase subunit I, ATP6: ATP synthase F0 subunit 6, CYT-b: cytochrome b.

based on genetic data obtained according to the European haplogroup characterization [35]. The percentages of each haplogroup for disease types are reported in Table 3.

\section{Discussion}

This study is focused on detecting mitochondrial genetic profiles specifically associated with pathological phenotypes of demyelinating diseases. Compared to previous studies [30] our strategy unconditionally assessed the whole $16 \mathrm{Kbs}$ of mitochondrial genome; this intensive analysis of our cohorts allowed us to search for genetic variants with a possible biological/clinical impact, present not only in coding genes, but also in non coding, regulatory regions where, as emerging evidence has been reported, variants affecting biological processes may occurs.

In order to cut off clinically irrelevant variants, we defined a specific reference sequence obtained from $7 \mathrm{HC}$ ' samples; this approach allowed us to highlight variants potentially linked to the onset of NMO, ON, My and RRMS in our cohort. We detected several unidentified variants, few of which may likely have a clinical impact due to their capacity to prematurely stop the translation of proteins with critical functions in the OXPHOS chain. Moreover, we identified several previously associated demyelinating pathologies described variants, strengthening the hypothesis of a direct correlation between variant occurrence and biological/clinical susceptibility to the disease development.

\section{Unknown variants}

Six not previously described nonsense mutations have been found in our study; 5 of them were in heteroplasmic conditions, while one occurred in homoplasmic condition in the sequence coding for cytochrome b (Leu238Stop). Nonsense mutations are genetic variants resulting in a shorter, unfinished protein product. These "truncating" mutations occur when a stop codon substitutes the proper amino acid 


\begin{tabular}{|c|c|c|c|c|c|c|c|c|c|c|c|c|c|c|c|c|c|c|c|c|c|c|c|c|c|}
\hline \multirow[b]{2}{*}{ Variant ID } & \multirow[b]{2}{*}{ nt change } & \multirow[b]{2}{*}{ aa change } & \multirow[b]{2}{*}{ Type } & \multirow[b]{2}{*}{$\begin{array}{l}\text { Interaction } \\
\text { domain }\end{array}$} & \multirow[b]{2}{*}{$\begin{array}{l}\text { Associated } \\
\text { disease }\end{array}$} & \multicolumn{4}{|c|}{ NMO } & \multicolumn{2}{|c|}{ ON } & \multirow{2}{*}{$\begin{array}{c}\text { My } \\
7\end{array}$} & \multicolumn{13}{|c|}{ RRMS } \\
\hline & & & & & & 1 & 2 & 3 & 4 & 5 & 6 & & 8 & 9 & 10 & 11 & 12 & 13 & 14 & 15 & 16 & 17 & 18 & 19 & 20 \\
\hline rs1599988 & $4216 \mathrm{~T}>\mathrm{C}$ & Tyr304His & mis & - & NMO, LHON & & & & $+/+$ & & & & & & & & & $+/+$ & & & & & & & \\
\hline rs28357980 & $4917 A>G$ & Asn150Asp & mis & - & NMO, LHON & & & & & & & & $+/+$ & & & & & & & $+/+$ & & & & & \\
\hline rs3021088 & $5460 \mathrm{G}>\mathrm{A}$ & - & syn & - & AD,PD & & & & & & & $+/-$ & & & & $+/-$ & & & & & & & & & \\
\hline rs28358270 & $9123 \mathrm{G}>\mathrm{A}$ & - & syn & TFBS (FOXC1) & DM CNS & & & & & $+/+$ & & & & & & & & & & & & & & & \\
\hline rs28575684 & $9647 \mathrm{~T}>\mathrm{A}$ & - & syn & miRNA & MS & & & & & & $+/-$ & $+/-$ & & & & & & & & & & & & & \\
\hline rs2854122 & $12705 \mathrm{C}>\mathrm{T}$ & - & syn & TFBS (ETS1) & MS, DM & & $+/+$ & & & & & & & & & & & & & & & & & & \\
\hline rs28359178 & $13708 \mathrm{G}>\mathrm{A}$ & Ala $>$ Thr & mis & - & $\begin{array}{c}\text { MS, LHON, } \\
\text { AD, PD }\end{array}$ & & & & $+/+$ & & & & & & & & & $+/-$ & $+/+$ & & & & & & \\
\hline rs41509754 & $13965 \mathrm{C}>\mathrm{T}$ & - & syn & - & MS & & & & & & & & & & & & & & & $+/+$ & & & & & \\
\hline rs41518645 & $15257 \mathrm{G}>\mathrm{A}$ & Asp171Asn & mis & - & LHON & & & & $+/+$ & & & & & & & & & $+/+$ & $+/+$ & & & & & & \\
\hline rs3094280 & $15663 A>G$ & Ile $>$ Val & mis & TFBS (ETS1) & MS, DM & & & & $+/+$ & & & & & & & & & & $+/+$ & & & & & & \\
\hline
\end{tabular}

Table 2: Features of Known Mitochondrial Variants Identified in the Study. +/- indicates the occurrence of mutation in heteroplasmic conditions while $+/+$ in homoplasmic conditions. RRMS: relapsing-remitting multiple sclerosis, NMO: neuromyelitis optica, ON: optic neuritis, My:myelitis, LHON: Leber's hereditary optical neuropathy, AD: Alzheimer's disease, PD: Parkinson's disease, MS: Multiple sclerosis, DM: demyelinating disease. ND1: NADH dehydrogenase subunit 1, ND2: NADH dehydrogenase subunit 2, ATP6: ATP synthase F0 subunit 6, CYC: cytochrome c oxidase subunit III, ND5: NADH dehydrogenase subunit 5, CYT-b: cytochrome b; mis: missense; syn: synonymous.

\begin{tabular}{|c|c|c|c|c|}
\hline Haplotype & NMO & ON & My & RRMS \\
\hline J & $75,00 \%$ & $100,00 \%$ & $100,00 \%$ & - \\
\hline H & $25,00 \%$ & - & - & $46,10 \%$ \\
\hline T & - & - & - & $15,40 \%$ \\
\hline X & - & - & - & $15,40 \%$ \\
\hline
\end{tabular}

Table 3: Percentage of Haplogroup occurring in Each Diseases' Groups and Healthy Controls. NMO: neuromylitis optica, RRMS: relapsing-remitting multiple sclerosis, ON: optic neuritis, My:myelitis. The number of samples for each group is indicated in parenthesis.

due to a nucleotide exchange. Several pathological conditions including myopathies, exercise intolerance, encephalomyopathies, lactic acidosis, and strokelike episodes have been described to be associated with mutations occurring in cytochrome b [36-38]. In particular, among these pathologies, exercise intolerance is a multisystem disorder that involves different syndromes including LHON; interestingly, the nonsense mutation, Leu238Stop mutation, occurred in a patient diagnosed with $\mathrm{ON}$, shortening the protein by 142 amino-acids (cutting about $37 \%$ of the protein off). Unfortunately, no other clinical or biological features of the sample are available, supporting the hypothesis of a direct correlation between mutation occurrence and disease development. However, it is likely that the deletion of more than $1 / 3$ of cytochrome 3 may deeply compromise Complex 3 and other functions of oxidative phosphorylation. As previously described, in fact, mutations within the mitochondrially encoded human cytochrome b gene (MTCYB) may lead to combined enzyme complex defects involving both complexes I and III. The absence of assembled complex III may results in a dramatic loss of complex I leading to specific clinical conditions including exercise intolerance [39].

All of the nonsense mutations except one (8528 $\mathrm{T}>\mathrm{C})$ occurred in two patients: one diagnosed with $\mathrm{ON}$ and the other with My. These mutations, detected in protein-coding for the genes ND1 (Gln173Stop), MT-CYT1 (Thr10Stop, Ser329Stop, Lys332Stop) and MT-CYTB (Leu238Stop) have an unknown clinical and biological impact; however, their capacity to prematurely stop the protein synthesis, leading to an incomplete protein synthesis and their concomitant occurrence in the same mitochondrial genome, synergistically contributing to the disruptive event, suggesting a possible role in the pathogenesis of diseases with overlapping features (i.e. ON, My).

\section{Variants previously described}

Online databases mentioned in the data analysis paragraph, allowed us to compare our findings with previously described genetic profiles. Nine of the detected variants had been previously described as able to increase the risk of CNS disease. In particular: rs1599988 missense variant, found in 2 of our patients, 1 with NMO and 1 with RRMS, was previously described in NMO [32] and in about $40 \%$ of the mtDNAs of European LHON patients [40,41, http://omim.org/ entry/516000\#0003]. Several other mutations in protein coding for gene ND1 have been found in LHON [13,40], multisystem atrophy, Leigh syndrome, Parkinson disease and various forms of encephalopathy [42], supporting the hypothesis that this gene is related to optic nerve pathologies and myelin abnormalities. Rs28358270 synonymous variant was identified in a ON patient. The nucleotide change from $\mathrm{G}$ to A occurred in the binding site for FOXC1 (forkhead box C1) transcription factor. FOXC1 showed DNA binding specificity through a selection of high affinity binding sites. Inactivation of this protein was reported [43] to be associated with demyelination of the cerebral white matter (WM), and may therefore be involved in the occurrence of neurodegenerative processes. Mutation in ATPase6 gene has been observed in another condition involving CNS and optic nerve such as NARP (neuropathy, ataxia, retinitis, pigmentosa) [13]. The synonymous variant rs28575684 was expressed in 2 of our patients, 1 with ON and 1 with My. This site was predicted (through the pupasuite online tool described before) to interact with specific microRNA: miRNA-27b. Micro-RNAs, are post-transcriptional regulators of gene expression, contributing to pathogenic T-cell differentiation in MS; miR-27b were increased in naïve memory CD4(+) T cells from patients with MS, inhibiting Th2 cell development and favouring pro-inflammatory Th1 responses [44]. Synonymous rs2854122 and missense rs3094280 variants were found in 1 NMO patient and 1 RRMS patient. These variants occurred in a binding site for ETS1 transcription factor. A study in a mouse model of MS reported that ETS1 might play a central role in the inflammation and demyelination processes [45]. The missense mutation (changing an Alanine into a Threonine) rs28359178 was detected in 1 NMO patient and in 2 RRMS patients. This variant, better known as $13708 \mathrm{~A}$, was associated 
Citation: Durastanti V, Monaco A, Caronti B, Cortese A, Fustaino V, et al. (2013) Mitochondrial Genome Profile in Demyelinating Diseases. J Neurol Neurophysiol 4: 179. doi:10.4172/2155-9562.1000179

in several studies with an increased risk of developing MS, LHON, Parkinson and Alzheimer disease [46,47]. Several other mutations in the protein coding gene ND5 have been found in LHON and MELAS (mitochondrial encephalomyopathy, lactic acidosis, strokelike episodes) reinforcing the belief that mutations in these genes are related to optical and CNS demyelinating pathologies [13,40].

\section{Haplotypes analysis}

As mentioned in previous publications, specific haplotypes were associated with higher risk of MS development. Interestingly, haplotype J only occurred in samples diagnosed with a degenerative disease. Unfortunately, the small sample size did not allow us to provide statistically significant information concerning haplogroups distribution. However, our preliminary analysis in line with previously published data $[2,46]$.

In conclusion, despite the limited number of samples of our cohort did not allow us to give a statistical significance to our findings, the study highlighted new insights on the clinical impact of mitochondrial genome's variants in neurodegenerative diseases; we looked not only for mutation with evident deleterious features, but also for variants that, occurring in non-coding regions, may affect the protein function through indirect mechanisms (such as interaction with transcription factor or other gene expression regulators such as miRNA). The use of most informative online databases allowed us to compare our results to previous findings and to confirm the presence of variants with a biological significance and likely showing a clinical impact. For some variants, which had not previously been identified, a possible biological deleterious function was provided, consistent with their occurrence in patients with neurodegenerative diseases.

\section{References}

1. Martin R, McFarland HF, McFarlin DE (1992) Immunological aspects of demyelinating diseases. Annu Rev Immunol 10: 153-187.

2. Ban M, Elson J, Walton A, Turnbull D, Compston A, et al. (2008) Investigation of the role of mitochondrial DNA in multiple sclerosis susceptibility. PLoS One 3: e2891.

3. Andrews HE, Nichols PP, Bates D, Turnbull DM (2005) Mitochondrial dysfunction plays a key role in progressive axonal loss in Multiple Sclerosis. Med Hypotheses 64: 669-677.

4. Dutta R, McDonough J, Yin X, Peterson J, Chang A, et al. (2006) Mitochondrial dysfunction as a cause of axonal degeneration in multiple sclerosis patients. Ann Neurol 59: 478-489.

5. Wingerchuk DM, Lennon VA, Pittock SJ, Lucchinetti CF, Weinshenker BG (2006) Revised diagnostic criteria for neuromyelitis optica. Neurology 66: 14851489.

6. Lennon VA, Wingerchuk DM, Kryzer TJ, Pittock SJ, Lucchinetti CF, et al. (2004) A serum autoantibody marker of neuromyelitis optica: distinction from multiple sclerosis. Lancet 364: 2106-2112.

7. Keegan M, Weinshenker B (2000) Familial Devic's disease. Can J Neurol Sci 27: S57-58.

8. Yamakawa K, Kuroda H, Fujihara K, Sato S, Nakashima I, et al. (2000) Familial neuromyelitis optica (Devic's syndrome) with late onset in Japan. Neurology 55: $318-320$

9. Lu M, Lee MD, Smith BL, Jung JS, Agre P, et al. (1996) The human AQP4 gene: definition of the locus encoding two water channel polypeptides in brain. Proc Natl Acad Sci U S A 93: 10908-10912.

10. Riordan-Eva P, Sanders MD, Govan GG, Sweeney MG, Da Costa J, et al. (1995) The clinical features of Leber's hereditary optic neuropathy defined by the presence of a pathogenic mitochondrial DNA mutation. Brain 118: 319-337.

11. Carelli V, Ross-Cisneros FN, Sadun AA (2004) Mitochondrial dysfunction as a cause of optic neuropathies. Prog Retin Eye Res 23: 53-89.

12. Harding AE, Sweeney MG, Miller DH, Mumford CJ, Kellar-Wood H, et al. (1992)
Occurrence of a multiple sclerosis-like illness in women who have a Leber's hereditary optic neuropathy mitochondrial DNA mutation. Brain 115: 979-989.

13. Di Mauro S (2001) Seminars in Cell and developmental biology 9: 397-405.

14. Dupuis $L$ (2013) Mitochondrial quality control in neurodegenerative diseases. Biochimie.

15. Kalman B (2006) Role of mitochondria in multiple sclerosis. Curr Neurol Neurosci Rep 6: 244-252.

16. Kalman B, Laitinen K, Komoly S (2007) The involvement of mitochondria in the pathogenesis of multiple sclerosis. J Neuroimmunol 188: 1-12.

17. Vyshkina T, Sylvester A, Sadiq S, Bonilla E, Canter JA, et al. (2008) Association of common mitochondrial DNA variants with multiple sclerosis and systemic lupus erythematosus. Clin Immunol 129: 31-35.

18. Su K, Bourdette D, Forte M (2013) Mitochondrial dysfunction and neurodegeneration in multiple sclerosis. Front Physiol 4: 169.

19. Nicholls D (2002) Mitochondrial bioenergetics, aging, and aging-related disease. Sci Aging Knowledge Environ 2002: pe12.

20. Kristal BS, Krasnikov BF (2003) Structure-(Dys)function relationships in mitochondrial electron transport chain complex II? Sci Aging Knowledge Environ 2003: PE3.

21. Brosnan CF, Cannella B, Battistini L, Raine CS (1995) Cytokine localization in multiple sclerosis lesions: correlation with adhesion molecule expression and reactive nitrogen species. Neurology 45: S16-21.

22. Calabrese V, Scapagnini G, Ravagna A, Bella R, Foresti R, et al. (2002) Nitric oxide synthase is present in the cerebrospinal fluid of patients with active multiple sclerosis and is associated with increases in cerebrospinal fluid protein nitrotyrosine and S-nitrosothiols and with changes in glutathione levels. J Neurosci Res 70: 580-587.

23. Koprowski H, Zheng YM, Heber-Katz E, Fraser N, Rorke L, et al. (1993) In vivo expression of inducible nitric oxide synthase in experimentally induced neurologic diseases. Proc Natl Acad Sci U S A 90: 3024-3027.

24. Zehntner SP, Bourbonniere L, Hassan-Zahraee M, Tran E, Owens T (2004) Bone marrow-derived versus parenchymal sources of inducible nitric oxide synthase in experimental autoimmune encephalomyelitis. J Neuroimmunol 150: $70-79$.

25. Ghafourifar P, Mousavizadeh K, Parihar MS, Nazarewicz RR, Parihar A, et al. (2008) Mitochondria in multiple sclerosis. Front Biosci 13: 3116-3126.

26. Johns DR, Hurko O, Attardi G, Griffin JW (1991) Molecular basis of a new mitochondrial disease: acute neuropathy and myelopathy. Ann Neurol 30: 234.

27. Cock H, Mandler R, Ahmed W, Schapira AH (1997) Neuromyelitis optica (Devic's syndrome): no association with the primary mitochondrial DNA mutations found in Leber hereditary optic neuropathy. J Neurol Neurosurg Psychiatry 62: 85-87.

28. Kalman B, Mandler RN (2002) Studies of mitochondrial DNA in Devic's disease revealed no pathogenic mutations, but polymorphisms also found in association with multiple sclerosis. Ann Neurol 51: 661-662.

29. Ghezzi A, Baldini S, Zaffaroni M, Leoni G, Koudriavtseva T, et al. (2004) Devic's neuromyelitis optica and mitochondrial DNA mutation: a case report. Neurol Sci 25: S380-382.

30. Hudson G, Mowbray C, Elson JL, Jacob A, Boggild M, et al. (2008) Does mitochondrial DNA predispose to neuromyelitis optica (Devic's disease)? Brain 131: e93.

31. Kalman B, Li S, Chatterjee D, O'Connor J, Voehl MR, et al. (1999) Large scale screening of the mitochondrial DNA reveals no pathogenic mutations but a haplotype associated with multiple sclerosis in Caucasians. Acta Neurol Scand 99: 16-25.

32. Celebisoy N, Akyurekli O, Copur A (2006) Devic's neuromyelitis optica: a case with mitochondrial DNA mutations. Eur Neurol 55: 93-95.

33. Samuels DC, Carothers AD, Horton R, Chinnery PF (2006) The power to detect disease associations with mitochondrial DNA haplogroups. Am J Hum Genet 78: 713-720.

34. Poser CM, Paty DW, Scheinberg L, McDonald WI, Davis FA, et al. (1983) New diagnostic criteria for multiple sclerosis: guidelines for research protocols. Ann Neurol 13: 227-231. 
Citation: Durastanti V, Monaco A, Caronti B, Cortese A, Fustaino V, et al. (2013) Mitochondrial Genome Profile in Demyelinating Diseases. J Neurol Neurophysiol 4: 179. doi:10.4172/2155-9562.1000179

35. Torroni A, Huoponen K, Francalacci P, Petrozzi M, Morelli L, et al. (1996) Classification of European mtDNAs from an analysis of three European populations. Genetics 144: 1835-1850.

36. Emmanuele V, Sotiriou E, Rios PG, Ganesh J, Ichord R, et al. (2013) A novel mutation in the mitochondrial DNA cytochrome b gene (MTCYB) in a patient with mitochondrial encephalomyopathy, lactic acidosis, and strokelike episodes syndrome. J Child Neurol 28: 236-242.

37. Massie R, Wang J, Chen LC, Zhang VW, Collins MP, et al. (2012) Mitochondrial myopathy due to novel missense mutation in the cytochrome c oxidase 1 gene. J Neurol Sci 319: 158-163.

38. Rana M, de Coo I, Diaz F, Smeets H, Moraes CT (2000) An out-of-frame cytochrome $b$ gene deletion from a patient with parkinsonism is associated with impaired complex III assembly and an increase in free radical production. Ann Neurol 48: 774-781.

39. Blakely EL, Mitchell AL, Fisher N, Meunier B, Nijtmans LG, et al. (2005) A mitochondrial cytochrome $b$ mutation causing severe respiratory chain enzyme deficiency in humans and yeast. FEBS J 272: 3583-3592.

40. Brown MD, Voljavec AS, Lott MT, Torroni A, Yang CC, et al. (1992) Mitochondrial DNA complex I and III mutations associated with Leber's hereditary optic neuropathy. Genetics 130: 163-173.
41. Johns DR, Berman J (1991) Alternative, simultaneous complex I mitochondrial DNA mutations in Leber's hereditary optic neuropathy. Biochem Biophys Res Commun 174: 1324-1330.

42. Vyshkina T, Banisor I, Shugart YY, Leist TP, Kalman B (2005) Genetic variants of Complex I in multiple sclerosis. J Neurol Sci 228: 55-64.

43. Kapoor S, Mukherjee SB, Shroff D, Arora R (2011) Dysmyelination of the cerebral white matter with microdeletion at 6p25. Indian Pediatr 48: 727-729.

44. Guerau-de-Arellano M, Smith KM, Godlewski J, Liu Y, Winger R, et al. (2011) Micro-RNA dysregulation in multiple sclerosis favours pro-inflammatory T-cellmediated autoimmunity. Brain 134: 3578-3589.

45. Gerhauser I, Alldinger S, Baumgärtner W (2007) Ets-1 represents a pivota transcription factor for viral clearance, inflammation, and demyelination in a mouse model of multiple sclerosis. J Neuroimmunol 188: 86-94.

46. Venkateswaran S, Zheng K, Sacchetti M, Gagne D, Arnold DL, et al. (2011) Mitochondrial DNA haplogroups and mutations in children with acquired central demyelination. Neurology 76: 774-780.

47. Yu X, Koczan D, Sulonen AM, Akkad DA, Kroner A, et al. (2008) mtDNA nt13708A variant increases the risk of multiple sclerosis. PLoS One 3: e1530.
This article was originally published in a special issue, Traumatic Brain Injury: Diagnosis \& Treatment handled by Editor(s). Dr. Douglas Mckay Wallace, University of Miami, USA 